\title{
Ectomycorrhizal fungal spore bank recovery after a severe forest fire: some like it hot
}

\author{
Sydney I Glassman ${ }^{1}$, Carrie R Levine ${ }^{1}$, Angela M DiRocco ${ }^{2}$, John J Battles ${ }^{1}$ \\ and Thomas D Bruns ${ }^{1,2}$ \\ ${ }^{1}$ Department of Environmental Science Policy and Management, University of California, Berkeley, Berkeley, \\ CA, USA and ${ }^{2}$ Department of Plant and Microbial Biology, University of California, Berkeley, Berkeley, CA, USA
}

\begin{abstract}
After severe wildfires, pine recovery depends on ectomycorrhizal (ECM) fungal spores surviving and serving as partners for regenerating forest trees. We took advantage of a large, severe natural forest fire that burned our long-term study plots to test the response of ECM fungi to fire. We sampled the ECM spore bank using pine seedling bioassays and high-throughput sequencing before and after the California Rim Fire. We found that ECM spore bank fungi survived the fire and dominated the colonization of in situ and bioassay seedlings, but there were specific fire adapted fungi such as Rhizopogon olivaceotinctus that increased in abundance after the fire. The frequency of ECM fungal species colonizing pre-fire bioassay seedlings, post-fire bioassay seedlings and in situ seedlings were strongly positively correlated. However, fire reduced the ECM spore bank richness by eliminating some of the rare species, and the density of the spore bank was reduced as evidenced by a larger number of soil samples that yielded uncolonized seedlings. Our results show that although there is a reduction in ECM inoculum, the ECM spore bank community largely remains intact, even after a high-intensity fire. We used advanced techniques for data quality control with Illumina and found consistent results among varying methods. Furthermore, simple greenhouse bioassays can be used to determine which fungi will colonize after fires. Similar to plant seed banks, a specific suite of ruderal, spore bank fungi take advantage of open niche space after fires.
\end{abstract}

The ISME Journal (2016) 10, 1228-1239; doi:10.1038/ismej.2015.182; published online 16 October 2015

\section{Introduction}

Conifer forests of the American West are adapted to fire. With evergreen vegetation maintained during an extended summer dry season, fire is inevitable (Noss et al., 2006). However, decades of fire suppression coupled to earlier spring snowmelt (Westerling et al., 2006) have changed the fire regime in some forest types from frequent, low-intensity events that cause little canopy death, to infrequent, large conflagrations termed 'mega-fires' that kill most of the trees (Stephens et al., 2014). Forest recovery in these radically altered post-fire environments may be constrained by distance to seed sources, extremes in microclimate and the absence of a mycorrhizal network (Stephens et al., 2014; Suz et al., 2015).

Although tree seedlings are able to survive short periods without ectomycorrhizal (ECM) fungal associates (Collier and Bidartondo, 2009), pine regeneration is often limited by lack of ECM fungal inoculum (Nunez et al., 2009). Thus, the initial

Correspondence: SI Glassman, Department of Environmental Science Policy and Management, University of California, Berkeley, 321 Koshland Hall, Berkeley, CA 94702, USA.

E-mail: sglassman@berkeley.edu

Received 20 March 2015; revised 28 August 2015; accepted 2 September 2015; published online 16 October 2015 recovery of forests after these severe mega-fires likely depends in part on whether appropriate ECM fungal spores have survived and are available to serve as partners for regenerating forest trees. In closed-cone pine forests, which historically thrive in high intensity, stand-replacing fire regimes, a subset of ECM fungi can survive in a soil spore bank as resistant spores or sclerotia (Baar et al., 1999). However, it is unclear if forests that historically experienced high-frequency, low-intensity fires, such as Pinus ponderosa, support ECM fungal spore banks that can survive high-intensity mega-fires.

Disturbances such as fires are important maintainers of diversity because they allow organisms to temporally divide niche space with competition colonization trade-offs (Sousa, 1984; Pacala and Rees, 1998). Although fire is likely to impose strong selective pressure on both plant and fungal communities (Archibald et al., 2013), it is challenging to study the effects of natural wildfire on microbial communities. Mega-fires are not well modeled by experimental, prescribed fires that are necessarily smaller and less severe.

Although there is a growing literature on fungal response to wildfire (Dahlberg et al., 2001; Treseder et al., 2004), only one previous set of studies exists in which pre-fire data were available for a wildfire 
event (Horton et al., 1998; Baar et al., 1999; Grogan et al., 2000), and this was less than a decade after the first application of PCR to the study of fungi (White et al., 1990). All other studies of post-fire ECM fungal recovery have primarily used space-for-time comparison where different aged fires were studied (Buscardo et al., 2010; Kipfer et al., 2011), laboratory heating experiments (Izzo et al., 2006; Peay et al., 2009; Kipfer et al., 2010) or low-intensity prescribed fires where host death was not involved (Stendell et al., 1999; Brown et al., 2013). Studying the effect of stand-replacing fire on fungi is particularly challenging because wildfire events are unpredictable and pre-fire data are seldom available.

For this reason, the California Rim Fire is an exceptional opportunity. It burned over 1000 square $\mathrm{km}$ in the Sierra Nevada Mountains of California in September 2013 and was the third largest fire in recorded California history. Such large, standreplacing forest fires are important to study because they are becoming more common due in part to climate change (Westerling et al., 2006) and to decades of successful fire suppression. Furthermore, the majority of hectares burned now occur in large stand-replacing fire events (Strauss et al., 1989). Although prescribed fires are useful research tools, they are not ideal models for wildfire, primarily because they differ from wildfires in levels of tree death, size of area burned and intensity. Fire size is especially important because fungi can be dispersal limited within distances of $<1 \mathrm{~km}$ (Peay et al., 2012; Adams et al., 2013). Thus, large wildfires may create a problem with fungal dispersal that is not encountered in small, prescribed burns.

Ecologists have long known that certain species of plants are specifically adapted to survive fire (Lamont, 1991) but are there analogous fungal species? Evidence from laboratory-based heating experiments show that certain ECM species such as Rhizopogon olivaceotinctus can survive temperatures up to $65^{\circ} \mathrm{C}$ (Peay et al., 2009). This is the same species that was the most frequent colonizer of pine seedlings after the 1995 Mount Vision fire (Baar et al., 1999). Thus, we have reason to believe that there are certain fungi adapted to fires (hereafter 'fire fungi') that have an increased ability to survive fire as resistant propagules in the spore bank. However, can results from a coastal, closed-cone pine forest be generalized to other pine forests?

The 2013 California Rim Fire, which was the single largest and most catastrophic fire in the history of the Sierra Nevada (Lydersen et al., 2014), provides an extreme test of whether ECM fungal spore banks can recover after mega-fires and whether there are specially adapted fire fungi. We had the opportunity to study this fire because two of our long-term study plots were located within the fire perimeter. In both plots, we had exceptionally highquality pre-fire data on the composition of the soil fungal community, the resident root community and the ECM fungal spore bank community (Talbot et al., 2014; Glassman et al., 2015).

To examine the effect of catastrophic fire on ECM fungal spore bank recovery, we sampled the plots within a month of the Rim Fire, conducted spore bank bioassays on the burned soil, planted in situ seedlings and identified the fungi using Illumina MiSeq sequencing of internal transcribed spacer (ITS) amplicons. With this data, we asked whether the ECM spore bank remained intact after the megafire and if spore bank fungi dominated the colonization of seedlings in the field. Furthermore, we asked if there are specific fire fungi that disproportionately survive in the ECM spore bank and thrive after a wildfire.

\section{Materials and methods}

Site description

Two $40 \mathrm{~m} \times 40 \mathrm{~m}$ plots located in the Stanislaus National Forest in the Sierra Nevada mountain range of California, named CA1 and CA2, were established in June 2011. Plots were selected with the help of local experts to contain even-aged monodominant stands of Pinus ponderosa. Soil cores were collected from the corners of nested squares $(5 \times 5 \mathrm{~m}$, $10 \times 10 \mathrm{~m}, 20 \times 20 \mathrm{~m}, 40 \times 40 \mathrm{~m})$ for a total of 13 samples per plot (Supplementary Methods S1). Stands in plots CA1 and CA2 were approximately 65 years in age and $98 \% \quad P$. ponderosa. See Supplementary Methods S2 for full plot characteristics and Supplementary Methods S3 for key sampling dates.

\section{Soil sampling and greenhouse bioassays}

For the initial sampling, hereafter referred to as prefire samples, 13 soil cores $\left(\sim 40 \mathrm{~cm}^{3}\right)$ were collected for analysis of the mature forest fungal community at each sample point. The organic $(\mathrm{OH})$ and mineral (AH) horizons were separated, sieved and fungi were characterized using 454 pyrosequencing (Talbot et al., 2014). Each soil horizon was analyzed for total carbon, total nitrogen, $\mathrm{pH}$, total extractable ammonium and nitrate content, and percentage of soil moisture as previously described (Talbot et al., 2014). Three additional soil cores were collected adjacent to each sample point and used for greenhouse-based pine seedling bioassays. These samples were sieved through 2-mm mesh to remove roots and rocks, homogenized by hand and air dried to kill active vegetative fungal hyphae (Taylor and Bruns, 1999). Hereafter, we refer to these as spore bank bioassays (Bonito et al., 2012; Glassman et al., 2015). Five replicates each of $P$. ponderosa and $P$. muricata were planted in separate $50-\mathrm{ml}$ Conetainers (Super 'Stubby' Cell Cone-tainer; Stuewe \& Sons Inc., Tangent, OR, USA) in soils from each of the 26 sampling locations. After 6 months, ECM 
fungal root tips were harvested and sequenced with 454 pyrosequencing (Glassman et al., 2015).

Plots CA1 and CA2 are well within the $>1000 \mathrm{~km}^{2}$ perimeter of the Rim Fire and were burned in September 2013. We re-sampled the plots within a month of the fire and re-established all sampling locations within $<1 \mathrm{~m}$ accuracy. Fire severity, calculated using the relative differenced normalized burn ratio at a $30 \mathrm{~m}$ pixel scale, was high in plot CA1 and moderate in CA2 (Lydersen et al., 2014). No pines survived in CA1, but four black oak (Quercus kelloggii) were killed to ground line and re-sprouted post-fire. In CA2, 90\% of canopy trees survived the fire, but they were heavily damaged with $>75 \%$ crown death in most trees. All subcanopy trees were killed in both plots (Figure 1).

We collected a soil core using the same corer as before at each sampling location in both plots on 31 October 2013, sieved through 2-mm mesh and air dried them for 3 weeks. Although the initial soil sampling involved both organic $(\mathrm{OH})$ and mineral
(AH) horizons, the fire burned off the $\mathrm{OH}$ leaving only the $\mathrm{AH}$ to sample post-fire. We measured soil moisture from all soils following air drying to ensure negligible water content (Supplementary Methods S4). Although pre-fire bioassays of plots CA1 and CA2 included $P$. ponderosa and $P$. muricata as hosts, no significant difference in retrieved communities was found by the two hosts (Glassman et al., 2015). However, $P$. muricata is easier to work with because unlike $P$. ponderosa, it does not require a long stratification to germination. In addition, $P$. muricata was found to be the best bioassay host to maximize recovery of ECM spore bank taxa across North America (Glassman et al., 2015). For these reasons, our post-fire bioassays used only $P$. muricata. To enable direct comparisons with pre-fire bioassay data, we planted five replicates of $P$. muricata seedlings for each sample point; five control plants per plot were planted into sterilized soil to detect greenhouse contamination. We planted a total of 140 plants $(2$ plots $\times 13$ samples $\times 5$ replicates +10 control
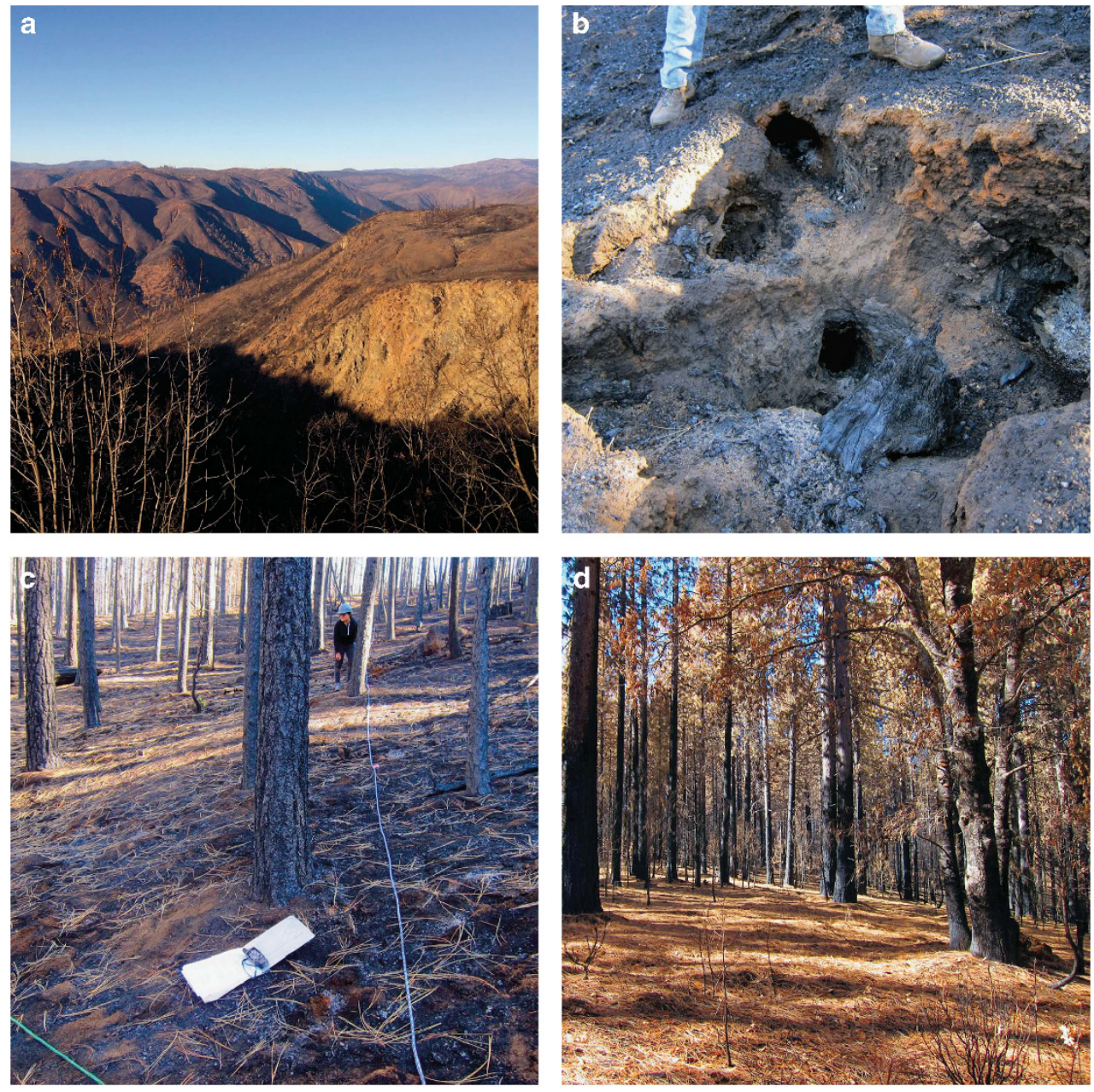

Figure 1 Rim Fire images: host death, extent and intensity are the fundamental differences between stand-replacing wildfires and prescribed burns. (a) The perimeter of the Rim Fire was $>1000 \mathrm{~km}^{2}$, with extensive tree mortality. (b) Heat release was high as evidenced by the numerous burned out stumps in the plots, and a change in soil color, texture, and increased hydrophobicity relative to unburned sites. (c) All pines in plot CA1 were killed by the fire, and the canopy was consumed by the flames. All organic matter, litter and all pine needles burned off. (d) Ninety percent of the pines survived in plot CA2, but over $75 \%$ of their crowns were killed, and all organic matter and litter burned off. Pine needles killed in the canopy covered the ground immediately after the fire. 
plants $=140$ ) and grew them in the UC Berkeley greenhouse for 6 months. Plants were watered every other day with tap water and randomized every other week for the duration of growth.

Although an independent control for the effect of temporal change on spore bank communities would have been ideal, unfortunately this temporal control was not feasible. The spatial extent of this fire was enormous ( $>1000 \mathrm{~km}^{2}$ ), and there were no unburned sites of a similar forest type for which pre-fire data were available that would not have also altered other potential drivers of change like host tree composition and structure, soil fertility, and elevation.

Furthermore, it is unlikely or irrelevant that temporal change in the spore bank that is independent from fire is feasible for several reasons. First, earlier work in California shows that spore banks are long lived (Bruns et al., 2009), spatially extensive and diverse. Soils can be diluted $>100$-fold into sterile soil and still colonize pine seedlings at high rates (Rusca et al., 2006), and the member taxa are primarily ruderals that were not present on the mature roots of the pre-fire trees (Glassman et al., 2015). Under these conditions, it is extremely unlikely that we would be able to detect a change over a 2-year time frame in a $>50$-year-old forest. Second, a study of ECM spore bank fungi colonizing Pinus strobus seedlings following catastrophic windthrows found very limited interannual variation (Cowden and Peterson, 2013). Third, seed banks appear to be an excellent model for spore banks (Glassman et al., 2015), and decades of research on plant seed banks indicate that there is very limited interannual variation in plant seed banks in mature forests (Pickett and McDonnell, 1989).

\section{Molecular identification of fungal species for post-fire} bioassays

Approximately six root tip clusters representing different ECM morphotypes were harvested from each bioassay plant, frozen at $-80^{\circ} \mathrm{C}$ and lyophilized. Root tips from all five replicates per sampling location were pooled and DNA was extracted following a modified version of the Qiagen (Valencia, CA, USA) DNAeasy Blood and Tissue Kit (Glassman et al., 2015).

We amplified ITS1, which is a part of the ITS, the universal DNA barcode for fungi (Schoch et al., 2012) using Illumina sequencing primers designed by Smith and Peay (2014). PCRs (see Supplementary Methods S5 for details) were cleaned using AMPure magnetic beads (Beckman Coulter Inc., Brea, CA, USA), quantified fluorescently with the Qubit dsDNA HS kit (Life Technologies Inc., Gaithersburg, MD, USA) and pooled at equimolar concentration. Libraries were quality checked for concentration and amplicon size using the Agilent 2100 Bioanalyzer (Agilent Technologies, Santa Clara, CA, USA) at the Functional Genomics Laboratory, University of
California, Berkeley, CA, USA, and sequenced with Illumina MiSeq PE $2 \times 300$.

\section{In situ seedlings}

To determine if ECM spore bank fungi recovered from post-fire bioassays colonized plants in the field, we planted $P$. ponderosa seeds at all sampling locations in plots CA1 and CA2. We acquired $P$. ponderosa seeds from the US Forest Service Placerville Nursery and planted them in the field on 6 November 2013. We broadcasted 100 seeds in a 1-m diameter circle and lightly buried them. Following natural stratification, germinated seedlings were first noticed in March 2014.

\section{Characterization of ECM colonization of in situ seedlings}

We collected approximately half of the surviving seedlings at each sampling location on 18 September 2014, 6 months after germination. We transported the seedlings on ice and processed them in the lab within 2 days of collection. Roots were rinsed in tap water and examined for colonization under the dissecting microscope. We collected ECM root tips from every seedling with sterilized forceps and pooled root tips from seedlings growing at the same sampling location. Root tips were then frozen at $-80^{\circ} \mathrm{C}$, lyophilized, and DNA was extracted, amplified and sequenced as described above.

\section{Molecular identification of species from pre-fire bioassay and in situ seedlings \\ To avoid confounding of comparisons between pre- and post-fire samples by different sequencing methods, we re-sequenced the DNA extracted from the pre-fire bioassay seedlings with Illumina Miseq (Glassman et al., 2015). The DNA extracted from both the pre-fire bioassays and the post-fire in situ seedlings was sequenced on the same run and the libraries were prepared with the same PCR primers and protocols described above.}

\section{Bioinformatics}

Illumina data were processed using a combination of the UPARSE (Edgar, 2013) and QIIME (Caporaso et al., 2010) pipelines following the methods of Smith and Peay (2014). A detailed description of the bioinformatics processing steps and results from those steps can be found in Supplementary Methods S6. Briefly, fastq files from the two Illumina MiSeq sequencing runs were concatenated, sequences were quality trimmed and reads were paired using USEARCH v7 (Edgar, 2013). Highquality sequences were grouped into operational taxonomic units (OTUs) using USEARCH (Edgar, 2013). Taxonomic assignments were made in QIIME based on the UNITE database (Koljalg et al., 2005). ECM fungal taxa were parsed from the OTU table 
using the filter_taxa_from_otu_table.py command in QIIME (Glassman et al., 2015) based on current knowledge of ECM fungal life history (Tedersoo et al., 2010). Sequences were submitted to the National Center for Biotechnology Information Sequence Read Archive under accession number SRP058508.

\section{Data quality control and analysis}

All analyses were based on the 95\% similarity OTU table parsed for ECM fungal taxa. There is growing concern that errors associated with high-throughput sequencing reduce the signal:noise ratio (Carlsen et al., 2012; Nguyen et al., 2014). In an effort to control this, we removed sequences based on negative (no DNA controls) and mock community samples composed of known taxa in known quantities that had been sequenced along with our experimental samples (details in Supplementary Methods S7 and Supplementary Methods S8). As analyses were robust regardless of whether or not sequences were removed based on these controls, we conclude that while these errors do add a low level of noise, the outcome of the analyses remains unaffected if the signal is strong. It is also necessary to rarefy samples to account for uneven sequencing depth. Thus, all analyses were run on an OTU table not rarefied, rarefied to 11532 sequences per sample to remove the bottom 10th percentile of samples with poor sequencing depth and rarefied to 13565 sequences per sample to remove the bottom 15th percentile. Although conclusions were robust regardless of treatment, presented analyses involved tables rarefied to 11532 sequences per sample resulting in a total of 48 ECM fungal OTUs.

To quantify the effect of the fire on the ECM spore bank community, we limited our analyses to differences in frequency of the fungi recovered from the pre- and post- fire bioassays. This avoided relying on read abundance, which is known to be inaccurate (Amend et al., 2010). By using the presence-absence data, we take an intentionally conservative approach to detecting differences in pre- and post-fire.

To quantify the effect of the fire on soil chemistry, we limited our analyses to the mineral horizon because the fire burned off the organic horizon in all samples. We calculated the sample mean, standard deviation, standard error for all soil nutrients before and after the fire and we conducted paired $t$-tests to detect changes in soil nutrients.

Changes in OTU frequency between the pre- and post-fire bioassays were visualized with rank abundance curves. Pearson product moment correlations were calculated to describe the relationship between the frequencies of ECM fungal OTUs present in the pre-fire vs post-fire bioassays. Differences in richness between the pre- and post-fire ECM fungal spore bank communities were quantified using sample based rarefaction curves with 95\% confidence intervals (CIs) generated by sampling with replacement (Colwell et al., 2004).
To determine if certain fire fungi increased or decreased in response to fire, we evaluated transition probabilities with an approach based on the multinomial probability distribution (Agresti, 2013). We defined three possible transitions using presence in the pre-fire bioassay seedlings as the reference condition: loss (present pre-fire and absent post-fire), no change (present or absent in both pre-fire and post-fire) and gain (absent pre-fire and present postfire). We took a two-step approach to reduce the chance of drawing spurious conclusions because of multiple comparisons. First, we identified taxa that deviated from the null expectation of no change; second, we calculated a robust estimate of the median transition probability using the rmultinom command in the stats package in R ( $\mathrm{R}$ Core Team, 2013). We assumed that the dominant probability in absence of disturbance (that is, the null response) was no change and then applied chi-squared goodness-of-fit tests to screen for species where losses and/or gains post-fire exceeded 10\%. For these taxa, we used a Monte Carlo simulation (1000 realizations) to estimate the median transition probabilities and their 95\% CIs. Transitions were considered significant if the 95\% CI of the simulations did not overlap 0. Significant probabilities of gain, loss or no change are not mutually exclusive; rather, multiple significant probability conditions indicate variation in response to fire among samples.

Similar methods were used to compare the ECM fungal OTUs colonizing the post-fire bioassay seedlings with those colonizing the post-fire in situ seedlings. This approach provided a direct comparison of how well the greenhouse assays mimic colonization in the field. The in situ seedling survival and colonization data were inspected with Pearson correlations to determine if there was a relationship between number of ECM fungal OTUs recovered per sample and either percentage of in situ seedlings colonized, and percentage of live or dead seedlings.

All analyses were conducted in $\mathrm{R}$ with the exception of species richness. Species accumulation curves were calculated with EstimateS (Colwell, 2013). Unless otherwise stated, all figures and all analyses use the following samples sizes: pre-fire bioassay seedling samples $(n=23)$, post-fire bioassay seedling samples $(n=25)$, post-fire in situ seedling samples $(n=23)$. Sample sizes are lower than 26 because some samples were lost during rarefaction because of poor sequencing depth, but include the true biological zeros where no seedlings were colonized at a given sampling location.

\section{Results}

Pre-fire communities predict post-fire communities ECM fungal spore bank OTUs recovered from pre- and post-fire bioassay seedlings are strongly positively correlated (Pearson $r=0.88, P<0.001$; 


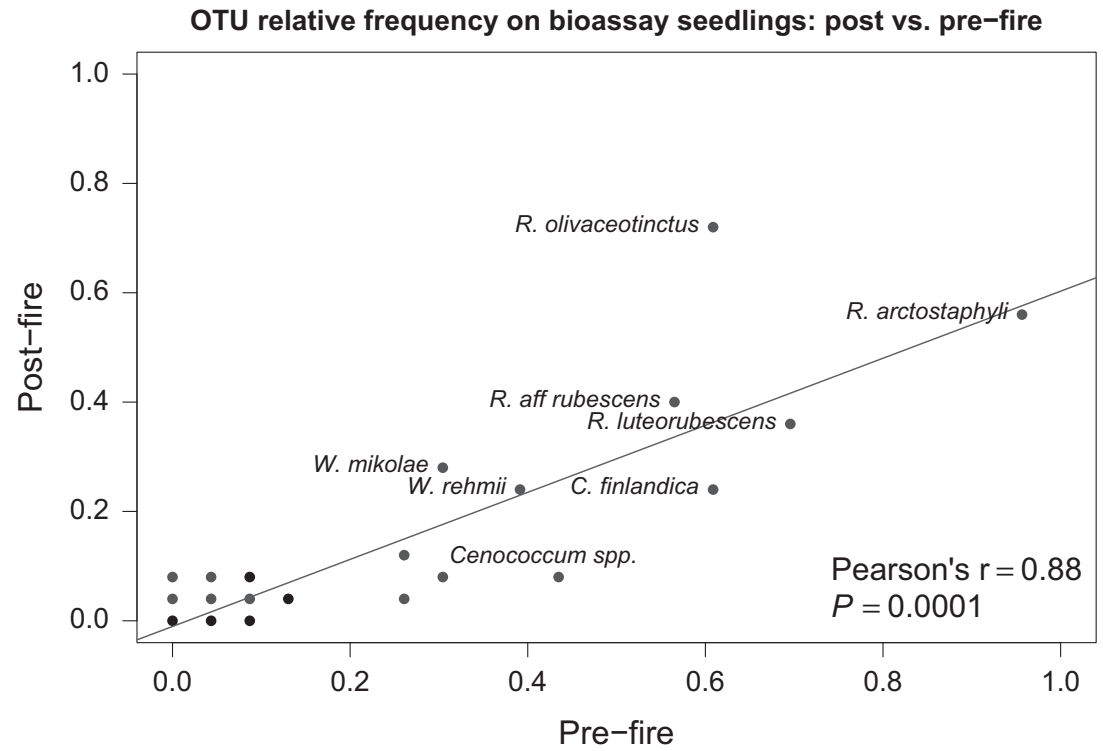

Figure 2 Correlation between relative frequencies of ECM fungal OTUs observed on pre- and post-fire bioassay seedlings. Points are transparent so darker circles indicate multiple points on top of each other.

Figure 2). This pattern is robust and does not change if the OTU table is rarefied to 13565 sequences per sample (Pearson $r=0.89, P<0.001$; Supplementary Figure S1A), or if the OTU table is not rarefied (Pearson $r=0.86, P<0.001$; Supplementary Figure $\mathrm{S} 1 \mathrm{~B})$. The 12 most frequent ECM fungal OTUs in the post-fire bioassay seedlings were all present in the pre-fire bioassay seedlings (Figure 3), and drive the correlation seen in Figure 2.

Effect of fire on soil chemistry

The fire burned off the $\mathrm{OH}$ horizon in all 26 samples. For the mineral horizon, the soil moisture was significantly lower after the fire $(\mathrm{M}=0.15$, s.d. $=0.01)$ than before the fire $(\mathrm{M}=0.24$, s.d. $=0.092, \mathrm{t}(25)=-4.84$, $P<0.001)$. The C:N ratio was also significantly lower after the fire $(M=20.6$, s.d.=2.59) than after the fire $(\mathrm{M}=26.8$, s.d. $=10.65, \mathrm{t}(22)=-3.03, P<0.001)$. There were no significant differences in percent $\mathrm{N}$, percent $\mathrm{C}$, extractable ammonium/nitrate or $\mathrm{pH}$ detected. Raw soil chemistry data available in Supplementary Table S1 and analyses summarized in Supplementary Table S2.

Effect of fire on spore bank richness and density Although the most abundant ECM fungal OTUs in both the pre- and post-fire bioassay seedlings were the same $(r=0.88, P<0.001$; Figures 2 and 3), ECM fungal spore bank richness was reduced in the postfire bioassay seedlings (Figure 4a). The statistical criterion for significance is non-overlap of 95\% CI of the estimates of richness. The pre-fire richness was 31.8 (95\% CI: 26.7-37.0), which was significantly greater than the post-fire richness of 20.0 (95\% CI: 16.8-23.1). The density of viable spores in the ECM spore bank was also reduced after the fire (results

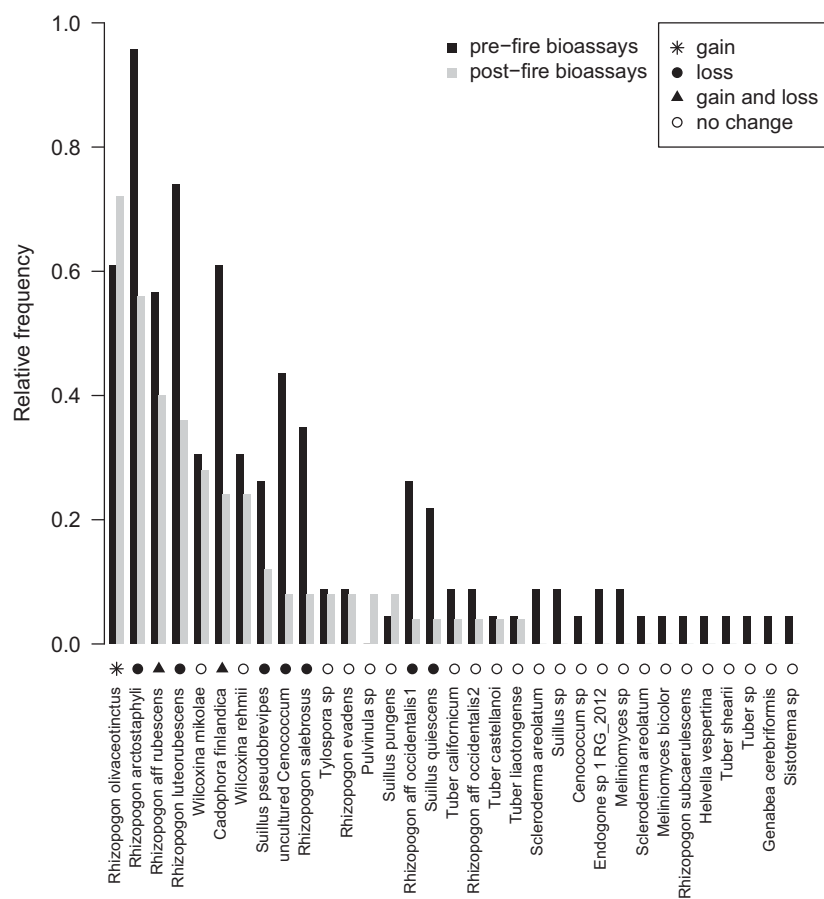

Figure 3 Rank abundance curve by frequency for ECM fungal OTUs recovered by pre- and post-fire spore bank bioassays. The axes represent the relative frequency of each ECM fungal OTU per total number of samples for either the pre- or post-fire bioassay seedlings. A single sample included roots of all of seedlings from a particular sample point. Shapes indicate the probability of no change (unfilled circle), gain (star), loss (filled circle), both gain and loss (triangle) of each OTU after the fire based on transition analysis. All OTUs had a significant probability of no change in addition to the significant probability of gain or loss.

summarized in Supplementary Table S3). For the pre-fire bioassays, $100 \%$ of the samples had colonized seedlings $(n=26)$. For the post-fire samples, $85 \%$ of the bioassays had colonized seedlings 

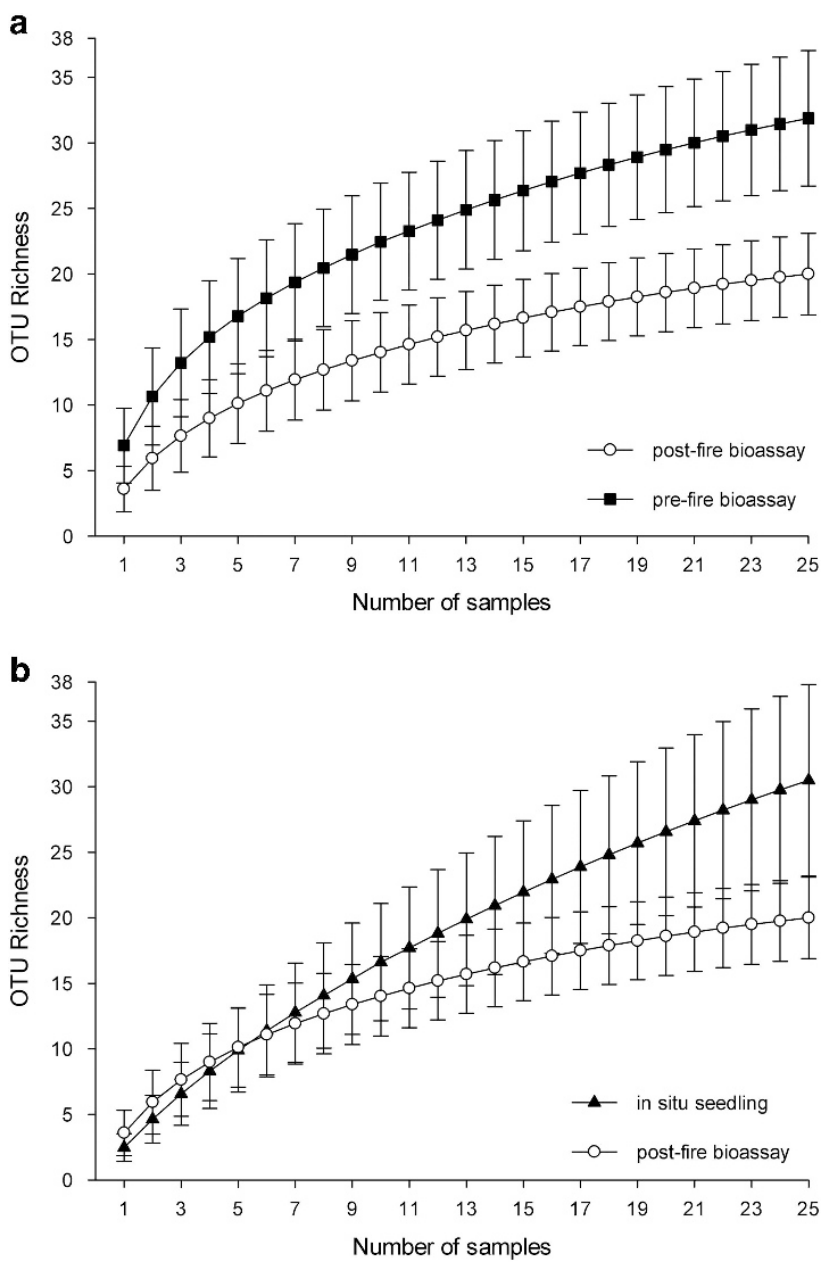

Figure 4 (a) Fire reduced ECM fungal spore bank richness in bioassays. (b) Richness was higher in in situ seedlings than in bioassay seedlings post-fire. Species richness curves with all treatments extrapolated to 25 samples. $95 \%$ CI based on 100 resamples without replacement.

$(n=22)$, and $69 \%$ of in situ samples had colonized seedlings $(n=18$; Supplementary Figure S2).

Post-fire in situ seedling survival and colonization Seedlings initially established at 25 of 26 sample locations. Number of live seedlings at each sampling location ranged from 0 to 72 with a mean and s.e. of $21.73 \pm 4.46$ live seedlings per sampling location. Percentage of seedlings that were colonized by ECM fungi at each sampling location ranged from 0 to 87.5 with a mean and s.e. of $23.45 \pm 4.34$ per sampling location (Supplementary Table S4). The number of ECM fungal OTUs per sample was strongly positively correlated with the percentage of seedlings colonized per sample $(r=0.58, \quad P<0.001$; Supplementary Figure S3A). There was no obvious relationship between the number of ECM fungal OTUs per sample and the percentage of live or dead seedlings per sample (Supplementary Figure S3); this pattern remained whether or not the OTU table was rarefied (Supplementary Figure S4). Number of a

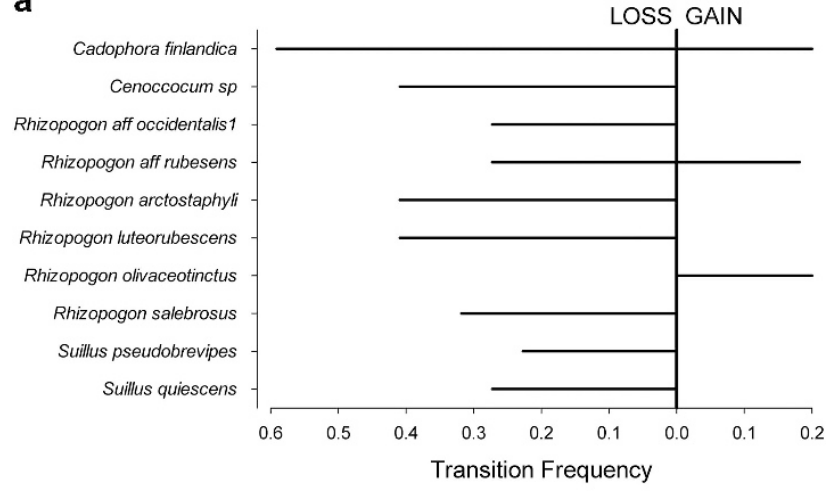

b

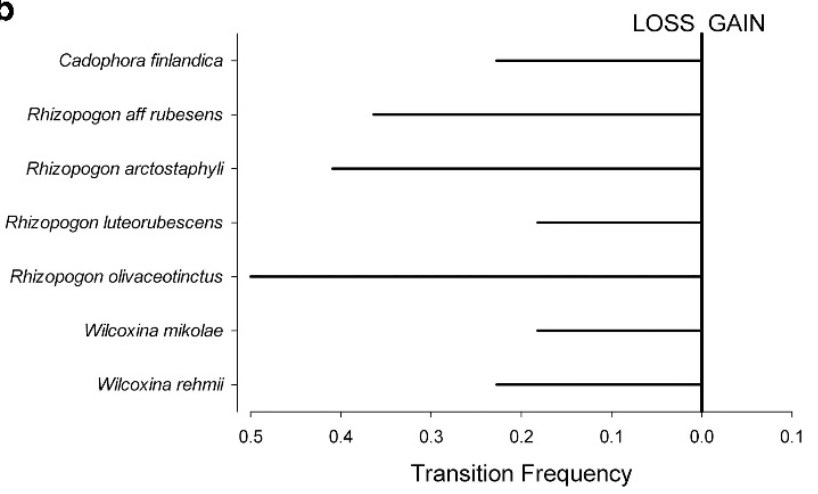

Figure 5 Probabilities of loss or gain in frequency of OTUs from (a) pre-fire bioassay seedlings to post-fire bioassay seedlings or from (b) post-fire bioassay seedlings to post-fire in situ seedlings. Only probabilities significantly $>0$ are shown. All other OTUs have $77-95 \%$ significant probabilities of no change.

ECM fungal OTUs on the in situ seedlings was higher than on the post-fire bioassay seedlings (Figure 4b). The richness of the in situ seedlings was 30.5 (95\% CI: 23.2-37.8), whereas the post-fire bioassays richness was 20.0 (95\% CI: 16.8-23.1).

Effect of fire on specific taxa for pre-fire versus post-fire bioassays

According to the Monte Carlo multinomial probability simulations, the most probable effect of fire on OTU presence was null (Supplementary Table S5). Of the 33 ECM fungal OTUs present in the bioassay seedlings, 23 had a strongly significant probability (ranging from $77 \%$ to $95 \%$ ) of no change in frequency post-fire. The chi-square goodness-of-fit test indicated that frequency of the other 10 OTUs deviated post-fire (Figure 5a; Supplementary Table S6). Of these taxa, only one species significantly increased in frequency after fire- $R$. olivaceotinctus. Two species, Cadophora finlandica and Rhizopogon aff rubescens, declined overall in frequency following fire (Figure 3), but varied so much among samples that both had significant, non-zero probabilities of increasing, decreasing or remaining unchanged after fire. The other seven species had a $23-41 \%$ probability of decreasing after the fire (Figure 5a). 
OTU relative frequency on post-fire seedlings: in situ vs bioassays

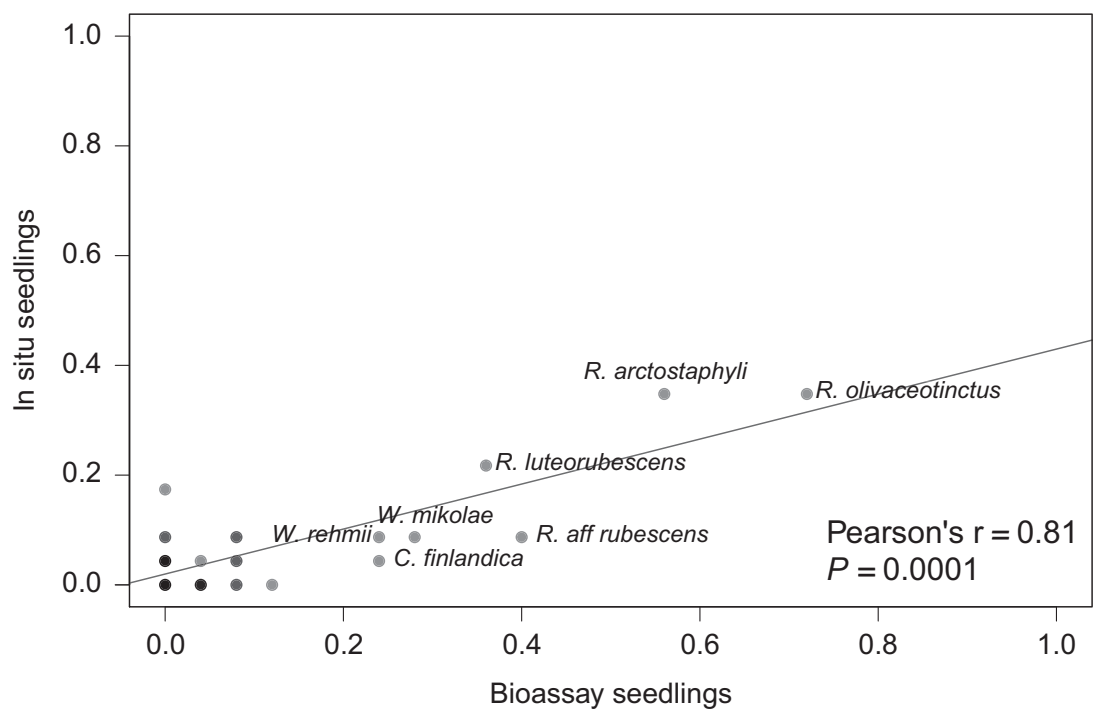

Figure 6 Correlation between relative frequencies of ECM fungal OTUs recovered from post-fire in situ seedlings and bioassay seedlings. Points are transparent so darker circles indicate multiple points on top of each other.

Concordance between greenhouse bioassays and field-based in situ seedlings

The ECM fungal spore bank OTUs recovered from post-fire bioassay seedlings were strongly positively correlated with those recovered from in situ seedlings (Pearson $r=0.81, P<0.001$; Figure 6). This pattern is robust to rarefaction (Pearson $r=0.81, P<0.001$, 13565 sequences per sample, Supplementary Figure S5A; Pearson $r=0.83, P<0.001$, no rarefaction, Supplementary Figure S5B). The most abundant ECM fungal OTUs in the in situ seedlings are present in both the pre- and post- fire bioassays (Figure 7, Supplementary Figure S6).

The transition analysis supports a strong correlation between the ECM fungal OTUs recovered from post-fire bioassays and the post-fire in situ seedlings. All 37 OTUs present in these samples had a $41-100 \%$ probability of no change from in situ to post-fire conditions, with most of the OTUs ranging from $82 \%$ to $100 \%$ probability of no change (Supplementary Table S7). Only 7 of the 37 OTUs present in these samples changed in frequency by $>10 \%$ (Supplementary Table S8), and these transitions all involved declines in frequency from the post-fire bioassays to the in situ seedlings (Figure 5b). No taxon had a $P>0$ of being present in the in situ seedlings but absent in the post-fire bioassays.

\section{Discussion}

The ECM spore bank fungi survived the fire and dominated the colonization of in situ and bioassay seedlings. As with plant seed banks, the ECM fungal spore bank is a reduced community, distinct from the mature forest soil fungal community, with few overlapping OTUs (Taylor and Bruns, 1999;

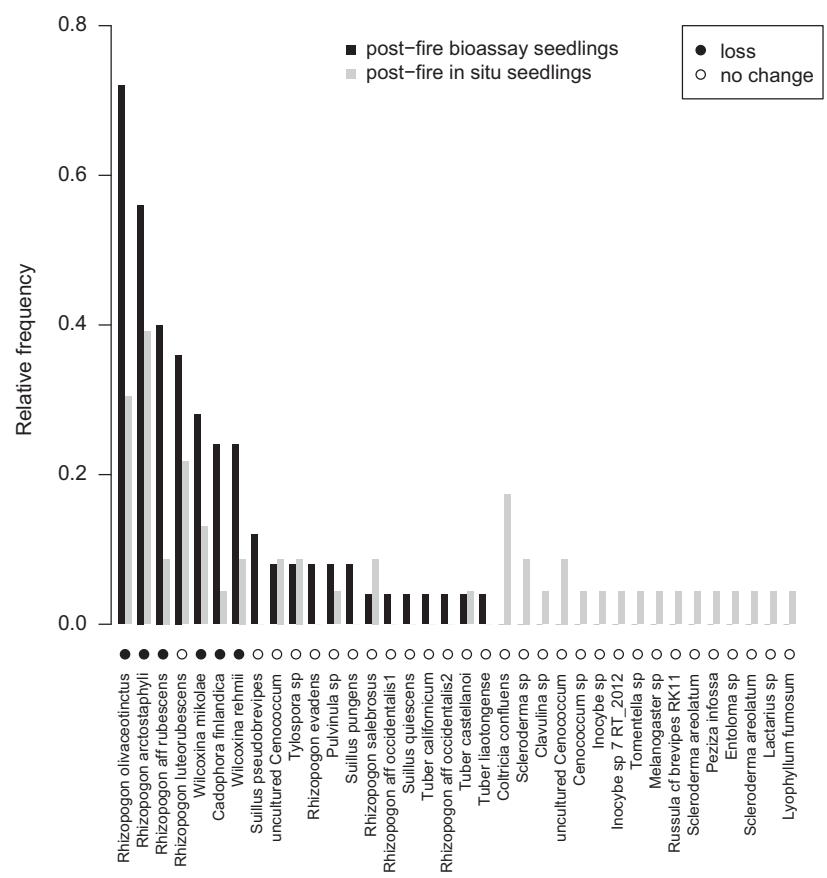

Figure 7 Rank abundance curve by frequency for ECM fungal OTUs recovered by post-fire bioassay and in situ seedlings. The axes represent the relative frequency of each ECM fungal OTU per total number of samples for either the post-fire bioassay or in situ seedlings. A single sample included roots of all of seedlings from a particular sample point. All OTUs had significant probability of no change (unfilled circle) according to transition analysis. Filled circle represents additional significant probability of loss from post-fire bioassay to in situ seedlings.

Glassman et al., 2015). The ECM fungal spore bank is a ruderal guild adapted to colonize roots quickly after a disturbance, and will likely have great importance for survival and growth of regenerating seedlings. Furthermore, there is evidence that certain 
fire fungi such as Rhizpogon olivaceotinctus specifically increase in abundance after a fire.

The Rim fire did not significantly alter ECM fungal spore bank community composition (Figure 2); neither did it shift the identities of the dominant ECM fungal taxa in the spore bank (Figure 3). This is remarkable especially considering that the pre-fire fungal spore bank communities came from a mixture of the $\mathrm{OH}$ and $\mathrm{AH}$ horizons, whereas the post-fire samples were completely lacking in $\mathrm{OH}$ horizon. However, it did reduce ECM spore bank diversity (Figure 4a) and density (Supplementary Table S1; Supplementary Figure S2). Post-fire impoverishment involved loss of low-frequency species (Figures 2 and 3), which suggests that taxon persistence is primarily driven by spore abundance. Laboratory manipulations show that heat reduces spore viability (Izzo et al., 2006; Kipfer et al., 2010) but species differ in their ability to survive heat, with $R$. olivaceotinctus spores exhibiting especially high tolerance (Peay et al., 2009). Our results are therefore consistent with those of previous laboratory manipulations (Izzo et al., 2006; Peay et al., 2009), greenhouse studies of ECM spore banks (Izzo et al., 2006), and the 1995 Mount Vision Fire study (Baar et al., 1999), all of which found that wildfires generally reduced ECM spore bank richness, but that Rhizopogon species increased in abundance.

Although the overall ECM fungal spore bank communities remained largely unchanged by the fire, there is nevertheless evidence for species-specific fire responses. Indeed, our results largely corroborate those of a laboratory manipulation in which spores were heated, live-dead stained and counted using flow cytometry. In that study, spore viability in $R$. olivaceotinctus was greater than Laccaria proxima, $R$. salebrosus or Suillus pungens after prolonged exposure to $65^{\circ} \mathrm{C}$ heat (Peay et al., 2009). We found that after fire, $R$. olivaceotinctus increased in frequency, whereas $R$. salebrosus and two species of Suillus decreased (Figure 5a). Similarly, R. olivaceotinctus and $R$. arctostaphyli were the most frequent colonizers of Pinus jeffreyi seedlings in greenhouse bioassays grown in soil experimentally heated to $75^{\circ} \mathrm{C}$ (Izzo et al., 2006), whereas heating tended to decrease the frequency of Cenococcum geophilum and Wilcoxina spp. In our study, $R$. olivaceotinctus and $R$. arctostaphyli were the most frequent colonizers of $P$. ponderosa seedlings in the field and, whereas neither species of Wilcoxina significantly changed in frequency after the fire, one species of Cenococcum had a significant probability of decreasing after the fire (Figures 3 and 5a). This result has important implications for fungal conservation: $R$. olivaceotinctus fruiting bodies have been considered so infrequent that the species has been listed as one of special concern (Castellano et al., 2003), yet it seems to be highly abundant in soil spore banks; ready to take advantage of niche space opened by fire.

Our results indicate that all of the most frequent species and the overall majority of post-fire ECM that colonized in situ seedlings come from spore bank fungi that persisted as propagules in the soil. This conclusion is supported by the strong correlation between the ECM fungi that colonized the pre- and post-fire bioassays (Figure 2), the correlation between these communities and those that colonized the in situ seedlings (Figure 6), and the transition analysis, which found that all taxa had a strong, significant probability of no change in frequency after the fire (Supplementary Table S7). This is important because it indicates that there is an ECM community that survives intense wildfire that can immediately assist with reforestation.

Although the fire reduced ECM fungal richness in the bioassays (Figure 4a), the richness observed in the in situ seedlings was higher than that in the bioassays (Figure 4b). This observation may have been caused by enhanced post-fire dispersal, by inoculum sources present in the soil that do not respond to greenhouse conditions or by access of in situ seedlings to a greater volume of soil than that available to the bioassay seedlings in pots. Post-fire dispersal is a possibility because soil for the post-fire bioassays was collected in October 2013, whereas the in situ seedlings were not collected until nearly a year later. Only the rare species were not observed in the spore bank (Figure 7). Thus, even if additional species were contributed by dispersal, they account for a very small percentage of the community in the first year following this fire, indicating the importance of strong priority effects (Kennedy et al., 2009).

Although Illumina sequencing of $16 \mathrm{~S}$ ribosomal RNA to detect bacterial diversity has been common for years (Caporaso et al., 2011), the technology has been more difficult to apply to fungi. Designing primers to successfully amplify ITS amplicons with Illumina MiSeq is a recent advance (Smith and Peay, 2014) and many questions about appropriate data quality control remain (Nguyen et al., 2014). Researchers are conflicted over appropriate ways to deal with uneven sequencing depth (McMurdie and Holmes, 2014), and how to use negative controls and mock communities to calibrate bioinformatic pipelines (Bokulich et al., 2013; Nguyen et al., 2014). We took great pains to account for uneven sequencing depth, mock communities and negative controls with our analyses. What we found was that if the pattern is strong, the sequencing errors only add noise. Similar to another studying applying Illumina MiSeq to sequencing of ITS amplicons (Kennedy et al., 2014), analyzing the data with and without rarefaction yielded similar results. Ultimately, no matter how the OTU table was treated, the data analyses were always consistent.

Fire is a strong selective factor affecting both plant and animal communities in the American West (Archibald et al., 2013). It appears that analogous to plants, there is a specific suite of fungi that are adapted to fire. The Rim Fire reduced the fungal community from >100 ECM species in the mature forest before the fire (Supplementary Table S9) to 
approximately 30 ECM fungal species colonizing the in situ seedlings, and these 30 were also dominated by species of Rhizopogon (Figure 7). Similarly, the mature forest fungal community in Point Reyes National Seashore, where the Mount Vision Fire occurred, was dominated by a larger and more diverse community than the ECM spore bank, which was dominated largely by species of Rhizopogon (Taylor and Bruns, 1999). Species of Wilcoxina were frequent seedling colonizers after the Rim Fire, and also frequent colonizers of $P$. muricata seedlings after the Mount Vision Fire (Baar et al., 1999), of $P$. contorta seedlings after the Huck fire in Wyoming (Miller et al., 1998) and of $P$. ponderosa seedlings after prescribed fires in Oregon (Fujimura et al., 2005). It therefore appears that, in the western USA, the main post-fire ECM fungi are drawn from the spore bank and belong to a predictable set of genera.

The observed concordance between colonization of greenhouse bioassays and seedlings in the field also suggests that simple greenhouse bioassays can be used to predict which ECM spore bank fungi will survive a wildfire. This observation supports an important assumption used by Glassman et al. (2015) in a continent-wide survey, which is that air-dried soil can simulate the effects of disturbance, and that its use in seedling bioassays can effectively predict which fungi will survive and dominate seedling communities follow fire disturbance.

In conclusion, the Rim Fire was a stellar example of what is now increasingly common in pine forests across North America-large, severe, mega-fires. This is the first and only belowground study of this emerging pattern. The reason stand-replacing fires are different than low severity fire is that the death of the host effectively destroys the existing mycorrhizal community. The only previous example of standreplacing fire (Baar et al., 1999) goes back to the restriction fragment length polymorphism stage of molecular ecology, the sample sizes were modest and it occurred in a pine forest type where standreplacing fires are the norm. In contrast, we had much better species-level resolution in this study with sequence-based next-generation data, good spatial sampling, and this fire burned in ponderosa pine forest that is normally maintained by frequent, low-intensity fires. In short, this is an exceptional look into a microbial-mediated process that is critical for reestablishment of the existing plant community, and it is occurring in the context of a changing fire regime that has at the least a continental, and more likely global impact.

\section{Conclusions}

By comparing our results with those of the Mount Vision fire and previous laboratory manipulations, we have found generalizable principles of post-fire recovery by ECM fungi. Our results show that although fire reduces ECM inoculum, the ECM spore bank largely remains intact. Although fire does reduce ECM fungal communities, a small subset of ECM spore bank fungi, particularly species of Rhizopogon and Wilcoxina, persist in the soil after disturbance and colonize regenerating seedlings. The Rim Fire was the largest recorded fire in the Sierra Nevada Mountains (Lydersen et al., 2014), and $P$. ponderosa forests are not adapted for standreplacing fires. Yet, ECM fungal inoculum survived the fire and successfully colonized in situ seedlings. This indicates that, as long as there is some dispersal of tree seeds, the application of mycorrhizal inoculum to burn sites should be unnecessary.

As with the plant secondary successional literature, where there is a seed bank guild that emerges after a disturbance that is different from the dominant plants before the disturbance (Hopfensperger, 2007), there is a specific suite of ruderal spore bank fungi that take advantage of open niche space after fires kill off their superior competitors. This is the basis for succession and has important implications for maintenance of diversity because it provides a mechanism for dividing niches temporally (Sousa, 1984). These ruderal spore bank fungi have specific adaptations for persistence and some are likely specifically adapted to heat tolerance. Our results suggest that we can predict which ECM fungi will colonize regenerating pine seedlings after a wildfire. We have some candidates for specific fire fungi, which opens the field of inquiry for determining the specific mechanisms used by these taxa for surviving fire.

\section{Conflict of Interest}

The authors declare no conflict of interest.

\section{Acknowledgements}

Thanks to J Talbot for soil chemistry analyses, JA Chung, DP Smith, S Branco, G Rosenfeld for help re-sampling the sites after the fire, E Hendrickson for helping set up the post-fire bioassays, G Mason for help planting $P$. ponderosa seedlings, E Vellinga and L Boddy for aid in collecting the in situ seedlings from the field, JA Chung for setting up the Illumina MiSeq library for the pre-fire bioassay and in situ seedlings, and to J Schimel, E Simms, and three anonymous reviewers for helpful comments on the manuscript. We thank the USFS Placerville Nursery for providing us with $P$. ponderosa seeds and the Stanislaus National Forest for allowing us to sample. This project was funded by the National Science Foundation Dimensions of Biodiversity program (award 1046115). SIG was supported by the National Science Foundation Graduate Research Fellowship Program.

\section{References}

Adams RI, Miletto M, Taylor JW, Bruns TD. (2013). Dispersal in microbes: fungi in indoor air are 
dominated by outdoor air and show dispersal limitation at short distances. ISME J 7: 1262-1273.

Agresti A. (2013). Categorical Data Analysis. John Wiley \& Sons: Hoboken, NJ, USA.

Amend AS, Seifert KA, Bruns TD. (2010). Quantifying microbial communities with 454 pyrosequencing: does read abundance count? Mol Ecol 19: 5555-5565.

Archibald S, Lehmann CER, Gomez-Dans JL, Bradstock RA. (2013). Defining pyromes and global syndromes of fire regimes. Proc Natl Acad Sci USA 110: 6442-6447.

Baar J, Horton TR, Kretzer AM, Bruns TD. (1999). Mycorrhizal colonization of Pinus muricata from resistant propagules after a stand-replacing wildfire. New Phytologist 143: 409-418.

Bokulich NA, Subramanian S, Faith JJ, Gevers D, Gordon JI, Knight R et al. (2013). Quality-filtering vastly improves diversity estimates from Illumina amplicon sequencing. Nat Methods 10: 57-U11.

Bonito G, Smith ME, Brenneman T, Vilgalys R. (2012). Assessing ectomycorrhizal fungal spore banks of truffle producing soils with pecan seedling trap-plants. Plant Soil 356: 357-366.

Brown SP, Callaham Jr MA , Oliver AK, Jumpponen A. (2013). Deep Ion Torrent sequencing identifies soil fungal community shifts after frequent prescribed fires in a southeastern US forest ecosystem. FEMS Microbiol Ecol 86: 557-566.

Bruns TD, Peay KG, Boynton PJ, Grubisha LC, Hynson NA, Nguyen NH et al. (2009). Inoculum potential of Rhizopogon spores increases with time over the first 4 yr of a 99-yr spore burial experiment. New Phytologist 181: 463-470.

Buscardo E, Rodriguez-Echeverria S, Martin MP, De Angelis P, Pereira JS, Freitas H. (2010). Impact of wildfire return interval on the ectomycorrhizal resistant propagules communities of a Mediterranean open forest. Fungal Biol 114: 628-636.

Caporaso JG, Kuczynski J, Stombaugh J, Bittinger K, Bushman FD, Costello EK et al. (2010). QIIME allows analysis of high-throughput community sequencing data. Nat Methods 7: 335-336.

Caporaso JG, Lauber CL, Walters WA, Berg-Lyons D, Lozupone CA, Turnbaugh PJ et al. (2011). Global patterns of $16 \mathrm{~S}$ rRNA diversity at a depth of millions of sequences per sample. Proc Natl Acad Sci USA 108: 4516-4522.

Carlsen T, Aas AB, Lindner D, Vralstad T, Schumacher T, Kauserud H. (2012). Don't make a mista(g)ke: is tag switching an overlooked source of error in amplicon pyrosequencing studies? Fungal Ecol 5: 747-749.

Castellano MA, Cazares E, Fondrick B, Dreisbach T. (2003). Handbook to Additional Fungal Species of Special Concern in the Northwest Forest Plan. In Service UF (ed), Portland, OR, USA.

Collier FA, Bidartondo MI. (2009). Waiting for fungi: the ectomycorrhizal invasion of lowland heathlands. J Ecol (Oxford) 97: 950-963.

Colwell RK, Mao CX, Chang J. (2004). Interpolating, extrapolating, and comparing incidence-based species accumulation curves. Ecology 85: 2717-2727.

Colwell RK. (2013), EstimateS: statistical estimation of species richness and shared species from samples, 9 edn.

Cowden CC, Peterson CJ. (2013). Annual and seasonal dynamics of ectomycorrhizal fungi colonizing white pine (Pinus strobus) seedlings following catastrophic windthrow in northern Georgia, USA. Can J For Res 43: 215-223.

Dahlberg A, Schimmel J, Taylor AFS, Johannesson H. (2001). Post-fire legacy of ectomycorrhizal fungal communities in the Swedish boreal forest in relation to fire severity and logging intensity. Biol Cons 100: 151-161.

Edgar RC. (2013). UPARSE: highly accurate OTU sequences from microbial amplicon reads. Nat Methods 10: 996-998.

Fujimura KF, Smith JE, Horton TR, Weber NS, Spatafora JW. (2005). Pezizalean mycorrhizas and sporocarps in ponderosa pine (Pinus ponderosa) after prescribed fires in eastern Oregon, USA. Mycorrhiza 15: 79-86.

Glassman SI, Peay KG, Talbot JM, Smith DP, Chung JA, Taylor JW et al. (2015). A continental view of pineassociated ectomycorrhizal spore banks: a quiescent functional guild with a strong biogeographic pattern. New Phytologist 205: 1619-1631.

Grogan P, Baar J, Bruns TD. (2000). Below-ground ectomycorrhizal community structure in a recently burned bishop pine forest. J Ecol 88: 1051-1062.

Hopfensperger KN. (2007). A review of similarity between seed bank and standing vegetation across ecosystems. Oikos 116: 1438-1448.

Horton TR, Cázares E, Bruns TD. (1998). Ectomycorrhizal, vesicular-arbuscular and dark septat fungal colonization of bishop pine (Pinus muricata) seedlings in the first 5 months of growth after wildfire. Mycorrhiza 8: $11-18$.

Izzo A, Canright M, Bruns TD. (2006). The effects of heat treatments on ectomycorrhizal resistant propagules and their ability to colonize bioassay seedlings. Mycol Res 110: 196-202.

Kennedy P, Nguyen N, Cohen H, Peay K. (2014). Missing checkerboards? An absence of competitive signal in Alnus-associated ectomycorrhizal fungal communities. PeerJ 2: e686.

Kennedy PG, Peay KG, Bruns TD. (2009). Root tip competition among ectomycorrhizal fungi: are priority effects a rule or an exception? Ecology 90: 2098-2107.

Kipfer T, Egli S, Ghazoul J, Moser B, Wohlgemuth T. (2010). Susceptibility of ectomycorrhizal fungi to soil heating. Fungal Biol 114: 467-472.

Kipfer T, Moser B, Egli S, Wohlgemuth T, Ghazoul J. (2011). Ectomycorrhiza succession patterns in Pinus sylvestris forests after stand-replacing fire in the Central Alps. Oecologia 167: 219-228.

Koljalg U, Larsson KH, Abarenkov K, Nilsson RH, Alexander IJ, Eberhardt U et al. (2005). UNITE: a database providing web-based methods for the molecular identification of ectomycorrhizal fungi. New Phytologist 166: 1063-1068.

Lamont BB. (1991). Canopy seed storage and releasewhat's in a name? Oikos 60: 266-268.

Lydersen JM, North MP, Collins BM. (2014). Severity of an uncharacteristically large wildfire, the Rim Fire, in forests with relatively restored frequent fire regimes. Forest Ecol Manag 328: 326-334.

McMurdie PJ, Holmes S. (2014). Waste not, want not: why rarefying microbiome data is inadmissible. Plos Comput Biol 10: e1003531.

Miller SL, McClean TM, Stanton NL, Williams SE. (1998). Mycorrhization, physiognomy, and first-year survivability of conifer seedlings following natural fire in Grand Teton National Park. Can J Forest Res 28: 115-122. 
Nguyen NH, Smith DP, Peay KG, Kennedy PG. (2014). Parsing ecological signal from noise in next generation amplicon sequencing. New Phytologist 205: 1389-1393.

Noss RF, Franklin JF, Baker WL, Schoennagel T, Moyle PB. (2006). Managing fire-prone forests in the western United States. Front Ecol Environ 4: 481-487.

Nunez MA, Horton TR, Simberloff D. (2009). Lack of belowground mutualisms hinders Pinaceae invasions. Ecology 90: 2352-2359.

Pacala SW, Rees M. (1998). Models suggesting field experiments to test two hypotheses explaining successional diversity. Am Nat 152: 729-737.

Peay KG, Garbelotto M, Bruns TD. (2009). Spore heat resistance plays an important role in disturbancemediated assemblage shift of ectomycorrhizal fungi colonizing Pinus muricata seedlings. $J$ Ecol 97: 537-547.

Peay KG, Schubert MG, Nguyen NH, Bruns TD. (2012). Measuring ectomycorrhizal fungal dispersal: macroecological patterns driven by microscopic propagules. Mol Ecol 21: 4122-4136.

Pickett STA, McDonnell MJ. (1989)Seed bank dynamics in temperate deciduous forestLeck Ma, Parker VT, Simpson RL (eds), Ecology of Soil Seed Banks Xxii +462p. Academic Press, Inc.: San Diego, CA, USA; London, England, UKIllus Maps, pp 123-148.

R Core Team (2013). R: A Language and Environment for Statistical Computing. R Foundation for Statistical Computing: Vienna, Austria.

Rusca TA, Kennedy PG, Bruns TD. (2006). The effect of different pine hosts on the sampling of Rhizopogon spore banks in five Eastern Sierra Nevada forests. New Phytol 170: 551-560.

Schoch CL, Seifert KA, Huhndorf S, Robert V, Spouge JL, Levesque CA et al. (2012). Nuclear ribosomal internal transcribed spacer (ITS) region as a universal DNA barcode marker for Fungi. Proc Natl Acad Sci USA 109.

Smith DP, Peay KG. (2014). Sequence depth, not PCR replication, improves ecological inference from next generation DNA sequencing. Plos One 9: e90234.
Sousa WP. (1984). The role of disturbance in natural communities. Annu Rev Ecol Syst 15: 353-391.

Stendell ER, Horton TR, Bruns TD. (1999). Early effects of prescribed fire on the structure of the ectomycorrhizal fungus community in a Sierra Nevada ponderosa pine forest. Mycol Res 103: 1353-1359.

Stephens SL, Burrows N, Buyantuyev A, Gray RW, Keane RE, Kubian R et al. (2014). Temperate and boreal forest megafires: characteristics and challenges. Front Ecol Environ 12: $115-122$.

Strauss D, Bednar L, Mees R. (1989). Do one percent of forest fires cause 99-percent of the damage. Forest Sci 35: 319-328.

Suz LM, Barsoum N, Benham S, Cheffings C, Cox F, Hackett L et al. (2015). Monitoring ectomycorrhizal fungi at large scales for science, forest management, fungal conservation and environmental policy. Ann Forest Sci; doi:10.1007/s13595-014-0447-4.

Talbot JM, Bruns TD, Taylor JW, Smith DP, Branco S, Glassman SI et al. (2014). Endemism and functional convergence across the North American soil mycobiome. Proc Natl Acad Sci USA 111: 6341-6346.

Taylor DL, Bruns TD. (1999). Community structure of ectomycorrhizal fungi in a Pinus muricata forest: minimal overlap between the mature forest and resistant propagule communities. Mol Ecol 8: 1837-1850.

Tedersoo L, May TW, Smith ME. (2010). Ectomycorrhizal lifestyle in fungi: global diversity, distribution, and evolution of phylogenetic lineages. Mycorrhiza 20: 217-263.

Treseder KK, Mack MC, Cross A. (2004). Relationships among fires, fungi, and soil dynamics in Alaskan Boreal Forests. Ecol Appl 14: 1826-1838.

Westerling AL, Hidalgo HG, Cayan DR, Swetnam TW. (2006). Warming and earlier spring increase western US forest wildfire activity. Science 313: 940-943.

White TJ, Bruns T, Lee S, Taylor J. (1990). Amplification and direct sequencing of fungal ribosomal RNA genes for phylogenetics. In Ma Innis, Dh Gelfand, Jj Shinsky, Tj White (eds), Pcr Protocols: A Guide to Methods and Applications Xviii+482p. Academic Press, Inc.: San Diego, CA, USA; London, UK, pp 315-322.

Supplementary Information accompanies this paper on The ISME Journal website (http://www.nature.com/ismej) 